равнительный анализ эффективности комбинированной топической терапии больных папуло-пустулезной формой акне легкой и средней степени тяжести

\author{
Ю.С. Кондратьева, Т.Н. Шепилева, О.А. Кокина, Е.А. Субботин
}

ГБОУ ВПО «Алтайский государственный медицинский университет» Минздрава России 656038 , г. Барнаул, пр. Ленина, д. 40

Цель исследования. Сравнение эфффективности и безопасности применения препаратов Азелик (15\% гель азелаиновой кислоты), 1\% клиндамицин гель и 0,1\% адапален гель в комплексной терапии больных акне легкой и средней степени тяжести.

Материал и методы. Открытое сравнительное исследование, в котором приняли участие 40 пациентов с папулопустулезной формой акне легкой и средней степени тяжести. Учитывались данные анамнеза, опроса, результаты объективного осмотра, оценка морфоофункциональных параметров кожи и динамики индекса качества жизни. Результаты и выводы. В результате лечения у всех больных к концу 6-й недели отмечалась разная положительная динамика кожного процесса в зависимости от вида комбинированной терапии. Применение геля Азелик приводит к повышению уровня увлажненности кожных покровов, снижению показателя себуметрии, степени выраженности рельесра кожного покрова, уровня пигментации.

Ключевые слова: акне, папуло-пустулезная форма, азелаиновая кислота, Азелик.

Контактная информация: julia_jsk@mail.ru. Вестник дерматологии и венерологии 2015; (3): 135_140.

\title{
A comparative analysis of the efficacy of a combined topical therapy in patients suffering from mild to moderate papulopustular acne
}

Yu.S. Kondratiyeva, T.N. Shepileva, O.A. Kokina, Ye.A. Subbotin

Altai Medical State University

Prospekt Lenina, 40, Barnaul, 656038, Russia

The goal of this study was to compare the efficacy and safety of Azelic (15\% gel of azelaic acid), $1 \%$ Clindamycin gel and $0.1 \%$ Adapalene gel as a complex therapy in patients suffering from mild to moderate acne.

Materials and methods. An open-label comparative study involving 40 patients suffering from mild to moderate papulopustular acne. The study was based on the medical history, a questionnaire form, physical examination results, assessment of morphological and functional skin parameters and dynamics of the life quality index (DLQI).

Key findings and conclusions. Positive dynamics of the skin process was observed by the end of Week 6 of the treatment depending on the combination treatment type. The administration of Azelic gel resulted in an increased moisture level of the skin and reduced sebometry indices, skin relief intensity and pigmentation level.

Key words: acne, papulopustular form, azelaic acid, Azelic. 
Aкне (acne vulgaris) - распространенное полиморфрное мультифракториальное воспалительное заболевание пилосебацейного комплекса, имеющее разнообразные клинические фрормы от самых легких - комедональных до крайне тяжелых форм, таких как флегмонозые, индуративные, кистозные акне. Результаты эпидемиологических исследований показывают, что заболеваемость акне в популяции оценивается в диапазоне от 85 до 93\%, и кроме того, наблюдается тенденция к росту частоты постпубертатной и персистирующей во взрослом возрасте угревой сыпи [1-3]. В любом возрасте как активная фаза заболевания, так и исход болезни связаны с развитием разнообразных косметически значимых вторичных изменений кожи, которые могут сопровождаться психоэмоциональными расстройствами, преимущественно депрессивного характера, приводящими к социальной дезадаптации, снижению качества жизни пациентов. Отмечено, что тяжесть психоэмоциональных расстройств, как правило, не коррелирует с объективным состоянием пациента [4, 5].

Современные исследования показали, что ведущим механизмом развития акне является воспаление, а также повышенная продукция измененного по составу кожного сала, нарушение процессов кератинизации в области сально-волосяного аппарата, избыточная способность кератиноцитов к сцеплению и гиперколонизация патогенными микроорганизмами, главным из которых является $P$. acnes [6-8].

Выбор методов лечения акне основывается на адекватной клинической оценке степени тяжести заболевания, характера высыпаний, типа кожи, наличия сопутствующей патологии, возраста пациента. Топическая терапия назначается всем больным независимо от степени тяжести заболевания и является обязательным компонентом терапевтического комплекса пациента с акне. Показанием же для назначения системной терапии являются акне средней и тяжелой степени тяжести, психосоциальная дезадаптация, а также образование рубцов и неэффрективность наружного лечения.

Для наружной терапии акне в настоящее время используются топические ретиноиды, антимикробные препараты (бензоил пероксид), антибактериальные препараты, комбинированные лекарственные средства, азелаиновая кислота, салициловая кислота [9].

Для лечения больных с легкой комедональной формой акне препаратами выбора являются топические ретиноиды (адапален, изотретиноин, третиноин), которые обладают себостатическим и противовоспалительным свойствами. Выраженная комедонолитическая активность и антикомедогенный эффект обусловлены их способностью регулировать процессы кератинизации и десквамации эпителия за счет воздействия на фолликулярный гиперкератоз [10-11]. Азелаиновая кислота (AK) составляет альтернативу топическим ретиноидам, воздействует на дополни- тельные звенья патогенеза акне. Азелаиновая кислота - естественная органическая кислота, молекула которой содержит 9 атомов углерода и две карбоксильные группы $\left(\mathrm{COOH}\left(\mathrm{CH}_{2}\right)_{7}-\mathrm{COOOH}\right)$, она не обладает мутагенными и тератогенными свойствами. AK обладает противомикробными, кератолитическими, противовоспалительными, антиоксидантными, антитирозиназными свойствами. Антибактериальный эфрфект АК обусловлен активным транспортом препарата внутрь бактерий. Другим важным эффректом является нормализация процессов кератинизации в сально-волосяном фолликуле с торможением биосинтеза белка клеточных мембран [10, 11]. Противовоспалительное действие АК связано с уменьшением метаболизма нейтрофилов и снижением выработки ими свободнорадикальных фрорм кислорода, а антиоксидантное действие обусловлено снижением выработки супероксидных и гидроксильных радикалов нейтрофильными гранулоцитами. Кроме того, АК подавляет активность тирозиназы посредством конкурентного ингибирования, т.е. способствует уменьшению пигментации кожи, за счет воздействия на ферментные системы активированных меланоцитов. На фоне лечения AK не формируется резистентности флоры. Таким образом, АК воздействует одновременно на несколько ключевых звеньев патогенеза акне, что отвечает современным представлениям о критерии эффективности фрармакологических препаратов [12].

Одним из препаратов АК, представленных на отечественном фрармакологическом рынке, является гель для наружного применения Азелик (15\% азелаиновая кислота), в состав которого, помимо АК, входит эмолент - сквалан, благодаря которому препарат оказывает увлажняющее действие, что важно при проведении длительной поддерживающей терапии и улучшения переносимости лечения.

Цель настоящего исследования - сравнение эфрфрективности и безопасности применения препаратов Азелик (15\% гель азелаиновой кислоты), 1\% клиндамицин гель, 0,1\% адапален гель в комплексной терапии больных акне легкой и средней степени тяжести.

\section{Материал и методы}

На базе кафедры дерматовенерологии ГБОУ ВПО «Алтайский государственный медицинский университет» Барнаула было проведено открытое сравнительное проспективное наблюдательное исследование в параллельных группах продолжительностью 6 нед. В исследовании приняли участие 40 больных папулопустулезной формой акне легкой и средней степени тяжести. В том числе 26 пациентов мужского пола в возрасте от 14 до 34 лет (средний возраст 20,7 4 4,4 года): $9(34,7 \%)-c$ папуло-пустулезной формой легкой степени тяжести, 17 (65,4\%) - со средней степенью тяжести; 14 - женского пола в возрасте от 14 до 34 лет (средний возраст 22,3 $\pm 6,9$ года): $8(57,1 \%)-$ с па- 
пуло-пустулезной формой легкой степени тяжести, $6(42,9 \%)$ - со средней степенью тяжести.

Собирали анамнез (длительность основного заболевания, перенесенные и сопутствующие заболевания, предшествующая терапия, аллергологический анамнез, принимаемые в данный момент препараты (системные и местные), проводили объективную оценку дерматологического статуса, а также у всех пациентов до и после терапии изучали морфоорункциональные параметры кожи (увлажненность, пигментация, себуметрия, степень выраженности рельефа кожного покрова) при помощи USB-видеокамеры SOMETECHINC с прикладным ПО. Расчеты и сохранение результатов исследования каждого параметра проводились при помощи программного обеспечения в базе данных.

Группу контроля при оценке морфоорункциональных параметров составили 10 добровольцев (6 мужчин и 4 женщины, средний возраст 24,8 \pm 0,9 года) без заболеваний кожи на момент осмотра и в анамнезе. Также проводился анализ динамики показателя дерматологического индекса качества жизни (ДИКЖ).

Пациентам, принявшим участие в исследовании, до начала терапии и на 6-й неделе лечения проведено общеклиническое обследование: общий анализ крови, общий анализ мочи, биохимический анализ крови (общий белок, общий билирубин, аланин-аспартатаминотрансфераза, щелочная фросфотаза, глюкоза, мочевина, креатинин).

Все пациенты в зависимости от клинической картины были разделены на две группы по 20 человек, рандомизированы по степени тяжести заболевания, полу и возрасту. В 1-ю группу вошли пациенты с папуло-пустулезной формой акне с преобладанием папул, во 2-ю группу - с папуло-пустулезной фрормой акне с преобладанием пустул. Внутри каждой группы в зависимости от проводимой терапии выделены две подгруппы: пациенты 1а подгруппы $(n=10)$ получали комбинированную терапию: Азелик гель 2 раза в день (утром, днем), 0,1\% адапален гель - 1 раз в день (вечером); пациентам 16 подгруппы $(n=10)$ назначалась монотерапия 0,1\% гелем адапалена - 2 раза в день (утром и вечером).

Пациенты 2а подгруппы $(n=10)$ получали комбинированную терапию: 1\% клиндамицин гель точечно на пустулы, Азелик гель на все другие проблемные участки 2 раза в день. Пациенты 26 подгруппы $(n=10)$ получали монотерапию: $1 \%$ клиндамицин гель на пустулезные элементы 2 раза в день.

Определение эффективности терапии, безопасности и переносимости препаратов во всех группах проводилось на 1, 2 и 6-й неделе лечения. Клиническая оценка эффрективности лечения проводилась по следующим критериям:

клиническое выздоровление - отсутствие эритемы или минимальная остаточная эритема. Отсутствие папул, пустул и шелушения;
- значительное улучшение - легкая эритема в центральной части лица, разрешение высыпаний не менее чем на 70\% по сравнению с исходными данными;

- улучшение - слабая или умеренная гиперемия в центральной части лица, единичные папулы и пустулы, незначительное шелушение, снижение выраженности патологического процесса не менее чем на 25\% по сравнению с исходными данными;

- незначительное улучшение - умеренная эритема лица, умеренное количество папул и пустул (уменьшение их количества в сравнении с исходным менее чем на 25\%), наличие жирных чешуек в складках;

- отсутствие эффректа - умеренная или тяжелая эритема по всему лицу, многочисленные папулы и/или пустулы, увеличение количества телеангиэктазий, значительное шелушение в складках.

Статистическая обработка и анализ данных проводились с использованием программы SPSS 13.0 forWindows (SPSS, Inc). Значения количественных величин представлены в виде $M \pm m$, где $M$ - выборочное среднее арифметическое и $m$ - стандартная ошибка среднего. Значения качественных признаков представлены в виде частот и процентов. В случаях нормального распределения для сравнения выборок использовали $t$-критерий Стьюдента. Если распределение отличалось от нормального, то использовали непараметрические критерии Манна - Уитни (для независимых выборок) и Вилкоксона (для связанных выборок). Для сравнения качественных признаков использовали критерий $\chi^{2}$. При наличии частот меньше 5 использовали точный метод Фишера. Уровень статистической значимости при проверке нулевой гипотезы принимали соответствующий $p<0,05$. При множественных сравнениях использовали поправку Бонферрони.

\section{Результаты и обсуждение}

При обследовании все 40 (100\%) пациентов предъявляли жалобы на наличие высыпаний на коже лица, у 8 (20\%) больных были жалобы на болезненность в области высыпаний, зуд беспокоил 5 (12,5\%) пациентов.

Среди сопутствующих заболеваний были выявлены: патология желудочно-кишечного тракта у $8(20 \%)$ больных, заболевания ЛОР-органов у $5(12,5 \%)$, заболевания эндокринной системы у $6(15 \%)$, заболевания нервной системы - у 3 (7,5\%) и бронхиальная астма - у 2 (5\%) больных.

При изучении генеалогического анамнеза выяснено, что у 15 (37,5\%) пациентов страдали акне отцы, у 8 (20\%) пациентов - матери. Оба родителя имели акне у $9(22,5 \%)$ участников исследования.

Анализ результатов общеклинического исследования крови и мочи, биохимического исследования крови больных во всех исследуемых группах до начала лечения и на фоне терапии не выявил отклонений от нормальных величин. 
В результате терапии у всех больных к концу 6-й недели терапии отмечалась разная положительная динамика кожного процесса (табл. 1). Причем клиническое выздоровление было достигнуто в подгруппах 1а и 2a у 2 (20\%) пациентов, в подгруппе 16 у 1 (10\%) больного; значительное улучшение отмечалось в подгруппе 1а у 4 (40\%) больных, в подгруппе 2 - - 5 (50\%) пациентов, в подгруппе 16 у 4 (40\%) больных и в подгруппе 26 у 1 (10\%). В остальных случаях все пациенты отмечали улучшение разной степени выраженности.

При анализе морфоорункциональных параметров кожи до начала терапии во всех исследуемых группах у пациентов с акне наблюдалось статистически значимое снижение уровня увлажненности кожных по- кровов, повышение степени выраженности рельефа кожного покрова, показателя себуметрии, уровня пигментации по сравнению с группой контроля (табл. 2).

К концу 6-й недели лечения у пациентов подгруппы 1а, получавших комбинированную терапию гелем Азелик и 0,1\% адапаленом, наблюдалось достоверное повышение уровня увлажненности кожных покровов, при этом достоверных различий с группой контроля не отмечалось $(p>0,05)$, в то время как в подгруппе $2 \mathrm{a}$ среднее значение данного показателя после лечения было достоверно ниже, чем в группе контроля $(p<0,05)$.

Среднее значение показателя себуметрии и степени выраженности рельефа кожного покрова в подгруппах 1а и 2а после лечения было достоверно ни-

Таблица 1 Результат лечения больных акне, абс. (\%)

\begin{tabular}{|c|c|c|c|c|c|c|c|c|}
\hline \multirow{3}{*}{ Результат лечения } & \multicolumn{2}{|c|}{ Подгруппа 1a $(n=10)$} & \multicolumn{2}{|c|}{ Подгруппа 2a (n= 10) } & \multicolumn{2}{|c|}{ Подгруппа 16 ( $n=10)$} & \multicolumn{2}{|c|}{ Подгруппа $2 б(n=10)$} \\
\hline & \multicolumn{8}{|c|}{ срок лечения } \\
\hline & 2 нед. & 6 нед. & 2 нед. & 6 нед. & 2 нед. & 6 нед. & 2 нед. & 6 нед. \\
\hline $\begin{array}{l}\text { Клиническое } \\
\text { выздоровление }\end{array}$ & 0 & $2(20)$ & 0 & $2(20)$ & 0 & $1(10)$ & 0 & 0 \\
\hline Значительное улучшение & $1(10)$ & $4(40)$ & $1(10)$ & $5(50)$ & $1(10)$ & $4(40)$ & 0 & $1(10)$ \\
\hline Улучшение & $3(30)$ & $3(30)$ & $2(20)$ & $2(20)$ & $3(30)$ & $4(40)$ & $2(20)$ & $3(30)$ \\
\hline $\begin{array}{l}\text { Незначительное } \\
\text { улучшение }\end{array}$ & $5(50)$ & $1(10)$ & $6(60)$ & $1(10)$ & $4(40)$ & $1(10)$ & $5(50)$ & $5(50)$ \\
\hline Отсутствие эффекта & $1(10)$ & 0 & $1(10)$ & 0 & $2(20)$ & 0 & $3(30)$ & $1(10)$ \\
\hline
\end{tabular}

Таблица 2 Морфофункциональные параметры кожи (в усл. ед.) в группах до и после терапии $(M \pm m)$

\begin{tabular}{|c|c|c|c|c|c|c|c|c|c|}
\hline \multirow{2}{*}{$\begin{array}{l}\text { Морфоорункциональный } \\
\text { параметр }\end{array}$} & \multirow{2}{*}{$\begin{array}{c}\text { Группа } \\
\text { контроля } \\
(n=10) \\
M \pm m\end{array}$} & \multicolumn{3}{|c|}{ Подгруппа 1a $(n=10)$} & \multicolumn{3}{|c|}{ Подгруппа 2a $(n=10)$} & \multicolumn{2}{|c|}{$P_{1 \mathrm{a}-2 \mathrm{a}}$} \\
\hline & & $\begin{array}{c}\text { до } \\
\text { лечения }\end{array}$ & $\begin{array}{l}\text { после } \\
\text { лечения }\end{array}$ & $p_{\text {A-n }}$ & $\begin{array}{c}\text { до } \\
\text { лечения }\end{array}$ & $\begin{array}{l}\text { после } \\
\text { лечения }\end{array}$ & $p_{\text {A-n }}$ & $\begin{array}{c}\text { до } \\
\text { лечения }\end{array}$ & $\begin{array}{c}\text { после } \\
\text { лечения }\end{array}$ \\
\hline $\begin{array}{l}\text { Увлажненность кожных } \\
\text { покровов }\end{array}$ & $34,5 \pm 5,2$ & $27,6 \pm 2,8^{*}$ & $29,9 \pm 2,6$ & 0,049 & $28,5 \pm 2,1^{*}$ & $27,7 \pm 2,2^{*}$ & 0,161 & 0,928 & 0,336 \\
\hline Себуметрия & $49,0 \pm 20,7$ & $89,5 \pm 9,6^{*}$ & $73,1 \pm 5,4^{*}$ & 0,003 & $90,8 \pm 8,5^{\star}$ & $72,1 \pm 6,2^{*}$ & $<0,001$ & 0,998 & 0,995 \\
\hline $\begin{array}{l}\text { Степень выраженности } \\
\text { рельесра кожного покрова }\end{array}$ & $55,3 \pm 15,5$ & $78,8 \pm 6,2^{*}$ & $67,8 \pm 3,4$ & 0,003 & $80,5 \pm 4,9^{*}$ & $65,5 \pm 3,9$ & 0,001 & 0,956 & 0,656 \\
\hline \multirow[t]{3}{*}{ Пигментация } & $22,0 \pm 14,2$ & $79,5 \pm 9,1^{*}$ & $51,3 \pm 10,6^{*}$ & $<0,001$ & $75,4 \pm 15,5^{\star}$ & $72,5 \pm 11,0^{*}$ & 0,427 & 0,950 & 0,006 \\
\hline & & \multicolumn{3}{|c|}{ Подгруппа $16(n=10)$} & \multicolumn{3}{|c|}{ Подгруппа 2б $(n=10)$} & \multicolumn{2}{|c|}{$P_{16-26}$} \\
\hline & & $\begin{array}{c}\text { до } \\
\text { лечения }\end{array}$ & $\begin{array}{l}\text { после } \\
\text { лечения }\end{array}$ & $p_{\text {A-n }}$ & $\begin{array}{c}\text { до } \\
\text { лечения }\end{array}$ & $\begin{array}{l}\text { после } \\
\text { лечения }\end{array}$ & $p_{\text {A-n }}$ & $\begin{array}{c}\text { до } \\
\text { лечения }\end{array}$ & $\begin{array}{c}\text { после } \\
\text { лечения }\end{array}$ \\
\hline Себуметрия & $49,0 \pm 20,7$ & $85,8 \pm 9,8^{*}$ & $65,5 \pm 7,6$ & $<0,001$ & $82,4 \pm 9,0^{*}$ & $81,1 \pm 8,9^{\star}$ & 0,060 & 0,929 & 0,008 \\
\hline $\begin{array}{l}\text { Степень выраженности } \\
\text { рельефа кожного покрова }\end{array}$ & $55,3 \pm 15,5$ & $74,4 \pm 7,5^{*}$ & $59,0 \pm 4,8$ & $<0,001$ & $76,5 \pm 5,8^{*}$ & $74,9 \pm 6,0^{*}$ & 0,003 & 0,954 & $<0,001$ \\
\hline Пигментация & $22,0 \pm 14,2$ & $73,4 \pm 12,7^{*}$ & $50,1 \pm 6,2^{*}$ & $<0,001$ & $70,6 \pm 9,7^{*}$ & $69,1 \pm 8,1^{*}$ & 0,164 & 0,982 & $<0,001$ \\
\hline
\end{tabular}

Примечание. $p_{\text {n-п }}$ - статистическая значимость различий между показателями до и после лечения; * - статистически значимые отличия ( $\left.p<0,05\right)$ от показателей контрольной группы. 
же, чем до начала терапии, однако среднее значение показателя себуметрии к концу 6-й недели лечения в обеих группах было достоверно выше, чем в группе контроля (см. табл. 2).

$\mathrm{K}$ концу 6-й недели лечения у пациентов подгруппы 1а наблюдалось значительное снижение среднего значения уровня пигментации с 79,5 \pm 9,1 до $51,3 \pm 10,6$ усл. ед. $(p<0,05)$, в то время как в подгруппе 2а наблюдалось незначительное снижение среднего значения данного показателя с 75,4 \pm 15,5 до 72,5 \pm 11,0 усл. ед., не достигшее уровня статистической значимости $(p>0,05)$. При этом средние значения уровня пигментации в подгруппах 1а и 2а после 6 нед. лечения $(51,3 \pm 10,6$ и 72,5 $\pm 11,0$ усл. ед. соответственно) имели статистически значимые различия $(p<0,05)$.

У пациентов подгруппы 1б, получавших комбинированную терапию - гель Азелик и 1\% гель клиндамицин, через 6 нед. лечения наблюдалось незначительное повышение уровня увлажненности кожных покровов с 27,3 \pm 1,2 до 29,4 $\pm 2,2$ усл. ед., не достигшее уровня статистической значимости $(p<0,05)$ (см. табл. 2). В подгруппе 26 наблюдалось достоверное повышение уровня увлажненности кожных покровов, однако значение данного показателя было достоверно ниже, чем в группе контроля $(27,8 \pm 1,7$ и 34,5 \pm 5,2 усл. ед. соответственно).

Отмечена тенденция к уменьшению уровня салоотделения кожи на фоне топической терапии с включением геля Азелик в подгруппе 1б, при этом средние значения показателя себуметрии в подгруппах 1 а и 26 после 6 нед. лечения $(65,5 \pm 7,6$ и 81,1 8 8,9 усл. ед.) имели статистически значимые различия $(p<0,05)$. Кроме того, среднее значение показателя себуметрии в подгруппе 1 было достоверно выше, чем в группе контроля (81,1 \pm 8,9 и 49,0 $\pm 20,7$ усл. ед. соответственно).

У пациентов подгрупп 16 и 26 наблюдалось значимое снижение показателя среднего значения степени выраженности рельефа кожного покрова (59,0 $\pm 4,8$ и 74,9 \pm 6,0 усл. ед. соответственно; $p<0,05)$. Помимо этого, среднее значение данного параметра после лечения в подгруппе 16 приближалось к значению в группе контроля и не имело статистически значимого различия $(p>0,05)$, в то время как в подгруппе 26 среднее значение данного показателя после лечения было достоверно выше, чем в группе контроля $(74,9 \pm 6,0$ и 55,3 $\pm 15,5$ усл. ед. соответственно; $p<0,05)$.

Среднее значение уровня пигментации в подгруппе 16 после лечения было достоверно ниже, чем до начала терапии $(50,1 \pm 6,2$ и 73,4 $\pm 12,7$ усл. ед. соответственно; $p<0,05)$, при этом в подгруппе 26 значение показателя осталось практически неизмененным. Средние значения уровня пигментации в подгруппах 16 и 26 после 6 нед. лечения $(50,1 \pm 6,2$ и 69,1 $\pm 8,1$ усл. ед. соответственно) имели статистически значимые различия $(p<0,05)$. Однако среднее значение уровня пигментации в обеих группах после терапии было достоверно выше, чем в группе контроля.

При анализе динамики показателя ДИКЖ (табл. 3) было отмечено, что до начала лечения во всех исследуемых группах заболевание оказывало сильное и чрезвычайно сильное (11-30 баллов) влияние на качество жизни пациентов: в подгруппе 1а у 6 (60\%) больных, в подгруппе 2 а - у 7 (70\%), в подгруппе 16 - у 4 (40\%), в подгруппе 26 - у 4 (40\%) обследуемых; умеренное влияние (6-10 баллов) - у 3 (30\%), $3(30 \%), 5$ (50\%) и 4 (40\%) пациентов соответственно; незначительное влияние или его отсутствие (0-5 баллов) - в подгруппе 1 а - у 1 (10\%), в подгруппе 16 - у 1 (10\%), в подгруппе 26 - у 2 (20\%) больных соответственно. На фоне терапии во всех исследуемых группах отмечалась тенденция к уменьшению количества больных, на которых акне оказывает сильное и чрезвычайно сильное влияние.

Нежелательных реакций, требующих отмены препарата, за отчетный период выявлено не было. На фоне лечения несколько пациентов отмечали появление сухости и шелушение кожи: в подгруппе 1а (Азелик гель и адапален гель) - у 2 (20\%) пациентов, в подгруппе 2a (адапален гель) - у 4 (40\%), в подгруппе 16 (Азелик гель и клиндамицин гель) - у 2 (20\%) пациентов. Чувство жжения после нанесения лекарственного средства наблюдалось у 1 (10\%) пациента из 1а подгруппы.
Таблица 3

Динамика показателя ДиКЖ в группах исследования во время лечения, абс. (\%)

\begin{tabular}{lcccccccc}
\hline & \multicolumn{2}{c}{ Подгруппа 1a $(n=10)$} & Подгруппа 2a $(n=10)$ & \multicolumn{2}{c}{ Подгруппа 16 $(n=10)$} & Подгруппа 2б $(n=10)$ \\
\cline { 2 - 9 } Показатель ДИКЖК & $\begin{array}{c}\text { до } \\
\text { лечения }\end{array}$ & $\begin{array}{c}\text { после } \\
\text { лечения }\end{array}$ & $\begin{array}{c}\text { до } \\
\text { лечения }\end{array}$ & $\begin{array}{c}\text { после } \\
\text { лечения }\end{array}$ & $\begin{array}{c}\text { до } \\
\text { лечения }\end{array}$ & $\begin{array}{c}\text { после } \\
\text { лечения }\end{array}$ & $\begin{array}{c}\text { до } \\
\text { лечения }\end{array}$ & $\begin{array}{c}\text { после } \\
\text { лечения }\end{array}$ \\
\hline $0-5$ баллов & $1(10)$ & $6(60)$ & 0 & $7(70)$ & $1(10)$ & $6(60)$ & $2(20)$ & $4(40)$ \\
\hline $6-10$ баллов & $3(30)$ & $4(40)$ & $3(30)$ & $3(30)$ & $5(50)$ & $4(40)$ & $4(40)$ & $5(50)$ \\
\hline $11-30$ баллов & $6(60)$ & 0 & $7(70)$ & 0 & $4(40)$ & $2(20)$ & $4(40)$ & $1(10)$ \\
\hline
\end{tabular}

Примечание. 0 -5 баллов — заболевание не оказывает или оказывает незначительное влияние на качество жизни; 6 - 10 баллов — умеренное влияние; $11-30$ баллов - сильное или чрезвычайно сильное влияние. 
У 1 (10\%) пациента в подгруппах 1a, 16 и 2а имелась преходящая незначительная гиперемия лица.

Таким образом, эфффективность терапии у пациентов с папуло-пустулезной формой акне с преобладанием папул в подгруппе 1а, получавших комбинированную топическую терапию - гель Азелик и 0,1\% гель адапален, оказалась сопоставима с эфффективностью терапии в подгруппе 2а у пациентов с папуло-пустулезной формой акне с преобладанием папул, применявших 0,1\% адапален. Но при этом переносимость терапии была выше в подгруппе 1а. Комбинация наружных препаратов геля Азелик и 0,1\% адапалена привела к снижению частоты развития побочных эффектов, наблюдаемых при использовании монотерапии топическими ретиноидами. У больных акне при использовании геля Азелик реже развивались сухость кожи и шелушение, наблюдалось повышение уровня увлажненности кожных покровов. Такой эффрект, повидимому, связан с тем, что в состав геля Азелик входит эмолент сквалан, который способствует увлажнению и восстановлению кожных покровов.

Эффрективность терапии у пациентов с папулопустулезной формой акне с преобладанием пустул в подгруппе 1б, получавших комбинированную топическую терапию гелем Азелик и 1\% клиндамицином, была выше, чем в подгруппе 26 у пациентов с папуло-пустулезной формой акне с преобладанием пустул, применявших $1 \%$ клиндамицин. Переносимость терапии в этих группах оказалась сопоставима. Кроме того, при включении в состав комплексной терапии геля Азелик наблюдалось снижение уровня пигментации.

\section{Выводы}

Результаты проведенного клинического исследования показали, что включение геля Азелик в состав комбинированной топической терапии приводит к снижению побочных эффректов, наблюдаемых при монотерапии топическими ретиноидами, и к повышению терапевтической эффрективности при сочетании с антибактериальными препаратами. Применение геля Азелик оказывает влияние на морфофрункциональные параметры кожи, приводя к повышению уровня увлажненности кожных покровов, снижению показателя себуметрии, степени выраженности рельефра кожного покрова и уровня пигментации.

Таким образом, полученные результаты показали высокую терапевтическую эффективность, хорошую переносимость и безопасность геля Азелик в лечении больных с папуло-пустулезной формой акне легкой и средней степени тяжести. I
1. Strauss J., Krowchuk D., Leyden J. et al. Guidelines of care for acne vulgaris management. J Am Acad Dermatol 2007; 56: 651_63.

2. Melnik B. Acne vulgaris. Dermatolog 2012; 4: 20_ 31. [Мельник Б. Обыкновенные угри. Дерматолог 2012; 4: 20-31.]

3. Samzov A.V. Acne and acneform dermatosis М: ЮТКОМ, 2009, 288 с. [Самцов А.В. Акне и акнеформные дерматозы. М: ЮТКОМ 2009; 288.]

4. Potekaev N.N., Goriachkina M.V. Certain aspects of diagnostics and treatment of refractory acne in the women. Clin Dermatol Venerol 2012; 1: 72-78. [П0текаев Н.Н., Горячкина М.В. Некоторые аспекты диагностики и лечения рефрактерных акне у женщин. Клин дерматол венерол 2012; 1: 72-78.]

5. Dreno B., Layton A., Zouboulis C.C. et al Adult female acne: a new paradigm J Eur Acad Dermatol Venereol 2013; 27: 1063-1070.

\section{Литература}

6. Goryachkina M.V., Belousova T.A. Combination therapy of acne in women: searching for optimum solutions. Vestn Dermatol Venerol 2014; 2: 90-95. [Горячкина М.В., Белоусова Т.А. Комбинированная терапия акне у женщин: поиск оптимальных решений Вестн дерматол венерол 2014; 2: 90—95.]

7. Thiboutot D., Gollnick H.P., Bettoli V., Dreno B. et al. New insights into the management of acne: An update from the Global Alliacne to improve outcomes in acne group. JAAD 2009: 60: 5: 1—50.

8. Araviyskaya Ye.R., Sokolovsky Ye.V. Systemic antibiotics therapy of acne: certain controversies. Vestn dermatol venerol 2013; 6: 177- 118. [Аравийская Е.Р., Соколовский Е.В. Системная антибиотикотерапия акне: некоторые дискуссионные вопросы. Вестн дерматол венерол 2013; 6: 177-118.]
9. Клинические рекомендации по ведению больных акне. Под ред. Кубановой А.А. М: ДЭКС-ПРЕСС 2010: 28.

10. Корсунская И.М., Тамразова О.Б., Бигвава С.С. Гель «Скинорен» В терапии розацеа. Росс журн кож вен бол 2005; 3: 37-40.

11. Waugh J., Noble S., Scott L.J. Adapalene: A Review of its Use in the Treatment of Acne Vulgaris. Drugs 2004; 64: (13): 1465-1478.

12. Dukhanin A.S. The current criteria for rational pharmacotherapy of acne in women. The viewpoint of a clinical pharmacologist. Clin Dermatol Venerol 2012; 2: 108-117. [Духанин А.С. Современные критерии рациональной фармакотерапии акне у женщин. Взгляд клинического фармаколога. Клин дерматол венерол 2012; 2: 108-117.]

об авторах:

Ю.С. Кондратьева - д.м.н., доцент, зав. касредрой дерматовенерологии ГБОУ ВПО АГМУ, Барнаул

Т.Н. Шепилева — врач-ординатор кафедры дерматовенерологии ГБОУ ВПО АГМУ, Барнаул

О.А. Кокина - к.м.н., ассистент кафедры дерматовенерологии ГБОУ ВПО АГМУ, Барнаул

Е.А. Субботин — К.м.Н., доцент кафедры физики и информатики ГБОУ ВПО АГМУ, Барнаул

\section{Конфликт интересов}

Авторы заявляют об отсутствии потенциального конфрликта интересов, требующего раскрытия в данной статье 